\title{
PETER SCHNEIDER
}

University of Augsburg

\section{Winfried Löffler. Einfuihrung in die Religionsphilosophie [Introduc- tion to Philosophy of Religion]. Darmstadt: Wissenschaftliche Buchgesellschaft, 2006.}

The book under consideration, authored by the Innsbruck philosopher Winfried Löfller, has as its purpose, according to the goals of the WBGseries Introductions to Philosophy, to deliver a systematic overview of the philosophy of religion, focusing on the results of contemporary research and debates. In this respect the book is very different from other German introductions to philosophy of religion which, in most cases, are characterised by a historical approach or a method which deals predominantly with significant authors in the field. Löffler's book, thus, has more in common with monographs arising out of the Anglo-American analytic philosophy of religion.

This introduction starts with a very dense chapter, that serves as an overview, in which the author explains his specific method and the outlines of his monograph. The chapter is followed by a really informative section dealing with the concept of philosophy of religion and its scientific status.

Löffler starts with a deliberately vague question: whether philosophical tools can reveal anything significant about religion. Stressing the problem of the plurality of religions and religious phenomena, which he illustrates by discussing the so called essentialistic and functional attempts to define the concept of religion, Löffler arrives at the conclusion that a general concept of religion cannot be furnished. Instead, he proposes to work with an open concept of religion whereby the word 'religion' is meant to signify a multitude of complex phenomena bound together by some sort of 'family resemblance' (borrowing the phrase from Wittgenstein). For hermeneutical reasons, Löffler focuses in his book on monotheistic religions, especially Christianity. He argues that a good acquaintance with one example of religion - a knowledge of one specific religious tradition from the inside - is a condition for the awareness of the aforementioned family resemblance. Löfler aims at showing that philosophy of religion 
is historically and factually dependent upon actual religions, although he seeks to underline the logical independence of philosophical arguments and truth-claims with respect to specific religious convictions. Despite the author's Christian affiliation, Löffler's book does justice to the proposed independence of philosophical arguments.

After distinguishing philosophy of religion from other disciplines dealing with religion - the history of religion, sociology of religion, and theology - Löffler places his approach within a spectrum of five types of philosophy of religion. His own approach is to be understood as a philosophical reflection on the reasonableness of religious convictions, especially with regard to their explanatory content and their truth-claims.

Consequently, the first two chapters of the main part of the book are dedicated to the question whether religious convictions are reasonable or not given their cognitive content, which resembles theories and which is expressed in propositions and truth-claims (cf. p. 46). Given Löffler's focus on monotheistic traditions, these theories coincide with proofs or disproofs of God's existence. Löffler treats a series of ten types of proofs for the existence of God. He considers several versions of the so-called ontological, cosmological, and teleological arguments, and also the types of arguments that are based on experience, by which he means either 'public' supernatural experiences (miracles), or more common individual religious experiences (valued by Reformed epistemology) and transcendental experiences (as understood by Karl Rahner or Wolfhart Pannenberg). Furthermore, Löffler discusses the so-called cumulative strategies (as proposed by Richard Swinburne and Basil Mitchell), as well as other types of proofs of God's existence - like Immanuel Kant's moral-theological argument or Pascal's wager.

The variety of attacks on the reasonableness of religious convictions is systematized by Löffler according to an idea stemming from Rudolf Carnap. This systematization is presented alongside a move from the most basic to the more refined criticisms. Hence, one will find in this section of the book a treatment of the charge of cognitive emptiness (Carnap, Flew), the charge of falsehood (Findlay, the problem of evil, the Darwinian explanation of the origin of religion), the charge that religious convictions lack justification and scientific content (Russell, Flew, Clifford), as well as a discussion of those arguments that claim religious convictions to be the 
result of failing cognitive faculties (Feuerbach, Marx, Freud), and finally the arguments suggesting that religious convictions are dangerous.

The main chapter of the book is devoted to analysis of the basic structure of each type of argument, in order to reveal its logical, ontological and epistemological prerequisites, which in turn makes possible the confrontation of these arguments with certain counter-arguments, leading to the assessment of their validity.

In doing so, Löffler offers an inspiring and very informative introduction to the topic in question. The benefit for the reader lies in becoming acquainted with contemporary discussions within a very complex area of research and debate. But Löffler's method has a price tag attached to it (of which the author seems aware). He removes the arguments from their historical contexts. In order to be able to clarify the structure of the arguments he has to clean up a certain vagueness which, perhaps, was a part of a given argument in its original form. The end result of such a clean-up looks more formal than the original argument itself. Still, Löffler is able to flesh out the discussion with a well-chosen series of illustrative examples.

However, what is left out of the picture are the arguments in favour of the reasonableness of religious convictions which have been developed within the framework of idealistic and Continental philosophy. For example, there is no mention of the notion of consciousness and self-consciousness (Klaus Müller, Dieter Henrich). The same goes for contemporary attempts to develop philosophies of religion following the idealistic traditions associated with the names of Hegel, Schelling or Peirce. Also missing are the arguments developed from the pragmatic standpoint, examples of which one might find in the most recent writings of Hilary Putnam. Although one might regret the fact that these elements of the debate are missing, Löffler's selective approach is understandable given the overwhelming abundance in this area of philosophy of religion.

The fifth chapter of the monograph starts with a summary of the main part of the book. Here, Löfller indicates that the debate over the reasonableness of religious convictions ends in a tie. According to Löffler, this does not imply that religion is bound to a non-cognitive realm altogether. Religion still has to deal with truth-claims and rational arguments, even if we have to concede that the reasonableness of religious convictions is different from that presupposed in scientific reasoning. Taking this as his 
point of departure, Löffler reflects on the so-called rational - i.e. rationally conceivable - structures of religion which place religious convictions within a sphere of rational reasoning that serves as some sort of umbrella for partial systems of everyday orientation in life. In the process Löffler uses the idea of a 'worldview' - an idea fostered by his teacher Otto Muck in Innsbruck.

According to Löffler and Muck, a worldview is a system of implicit and explicit convictions which is affected by experience and knowledge coming from different sources. A worldview has as its core certain leading and guiding concepts which may happen to be somewhat vague and metaphorical, but which still have the capacity to deliver a consistent general interpretation of reality. Religious convictions have the power to mould and to affect the concepts which are at the very core of a worldview.

In order to answer the question whether religious convictions can be rational, Löffler offers a set of criteria of rationality which he borrows from Frederick Ferré and Alfred N. Whitehead, and which he modifies, taking into account the specificity of theistic convictions. These criteria are: consistency, coherence, openness and being connected to experience. Löffler tries to justify the theistic worldview as something which is in accordance with a certain (namely Aristotelian) metaphysics, and which may serve as an integrative explanation and interpretation of reality and which does not lack cognitive content. Thus he shows that theism as a worldview is in the same position as any other worldview and is, therefore, able to bring different areas of experience together and to tie them together in a consistent, unequivocal and universal framework. In this regard Löffler develops the notion of 'integrative explanation' while distinguishing this idea from the concept of explanation used by the natural sciences and scientific reasoning. Löffler calls the latter a 'covering law' explanation. In doing so, Löffler establishes different layers of rational explanation.

In his summarizing remarks Löffler deals with the relevance of philosophy of religion for the concrete and existential side of religions. He is careful in assessing the impact of rational arguments for and against the reasonableness of religion by distinguishing between personal and interpersonal arguments and by pointing to the fact that in relation to religion personal and experientially-based arguments will have a deeper impact. Löffler points out that as in other areas of human life which 
confront philosophy, so also in the case of religion, there must be some sort of 'free certainty' which allows for personal application of certain types of arguments and for first-person involvement.

If this is the case, Löfller's discussion of various types of arguments serves two goals. On one hand, the discussion is meant to foster a reflection on religious convictions within the context of doubt and/or in the context of dialogue with other worldviews, in order to justify the reasonableness of beliefs in God's existence by providing inter-subjectively accessible arguments. On the other hand, this discussion contributes to a critical examination of the concept of God and of religious language as such.

Löffler's intellectually awake treatment of the reasonableness of religious convictions, based on the rationality of a worldview, is very inspiring. However, it is clear that Löffler's move to limit the discussion mainly to theism and to Aristotelian ontology (in order to illustrate the explanatory power of theism) itself shows that we are speaking about just one of various (historically valid) options. Given the different 'laws' governing theism and philosophy, one needs to be rather careful in mixing these two spheres of discourse. Instead, it might be necessary to clarify their connection based on more contemporary discussions within ontology and metaphysics.

Löffler's book is certainly a model of clarity. Its train of thought is persuasive and expresses a capacity to systematize a complex area of debate. Equally remarkable are the pedagogical skills which are revealed especially in the summaries at the end of each chapter, as well as in the recommendations for further reading. These hints allow for a deeper discussion of the topics and open up perspectives that go beyond the outlines of the book itself.

Having said that, the exclusive focus on the reasonableness of religious convictions reveals both the grandeur and the limitations of the book. For example, this focus tends to downplay the importance of various aspects of the concept of faith, as well as the impact of what one might call the 'religious form of life' and the so-called 'act of believing'. The problem of religious diversity and pluralism is also not considered. Despite these limitations, Löffler's monograph is an excellent textbook and can serve as an inspiring introduction to the contemporary philosophy of religion. 